\title{
Absolute Configuration, Optical Activity and Raman Microscopy of L and D- Glutamic Acid
}

Leonardo Y. Fox-Uribe ${ }^{1}$, Yedith Soberanes ${ }^{1}$, Valeria Guzman-Luna ${ }^{2}$, Gloria Saab-Rincon ${ }^{2}$, Javier Hernández-Paredes ${ }^{3}$ and Rogerio R. Sotelo-Mundo ${ }^{1}$

1. Laboratorio de Estructura Biomolecular, Centro de Investigación en Alimentación, y Desarrollo, A.C., Carretera a Ejido La Victoria km 0.6 s/n, Hermosillo, Sonora, C.P. 83304, México.

2. Departamento de Ingeniería Celular y Biocatálisis. Instituto de Biotecnología, Universidad Nacional Autónoma de México, Av. Universidad 2001, Cuernavaca, Morelos, 62210, México.

3. Posgrado en Nanotecnología, Departamento de Física, Universidad de Sonora (UNISON), Edificio 3R, Blvd. Luis Encinas J. y Rosales s/n Col. Centro, Hermosillo, Sonora, C.P. 83000, México.

Amino acids are the building blocks of proteins. Among this diverse group of molecules, glutamic acid $\left(\mathrm{Glu}-\mathrm{C}_{5} \mathrm{H}_{9} \mathrm{NO}_{4}\right)$ plays a key role as a component of enzymes, either with a structural role or as part of the catalysis in the active site to perform biological function [1]. Charged transfer RNAs are loaded with L stereoisomers, so proteins synthesized by the ribosome are exclusively comprised of L-amino acid residues. However, D-Glu is used in formation and development of bacterial peptidoglycan [2]. The determination of the absolute configuration of chiral compounds is critical in many fields of science and technology. In this work, we carried out single-crystal X-ray diffraction (SCXRD) experiments with $\mathrm{Cu}$ $\mathrm{K}_{\alpha}$ radiation to determine the absolute configuration of glutamic acid in both enantiomeric forms (L/D). L and D-Glu isomers were also analyzed to determine their optical activity and structural information.

The amino acids were purchased from Sigma-Aldrich and used without further recrystallization. The crystallization experiments were: 1) $50 \mathrm{mmol}$ of L-glutamic acid ( $\geq 99 \%$ pure); m.p.: 206-208 ${ }^{\circ} \mathrm{C}$. ${ }^{1} \mathrm{H}$ NMR ( $\left.\mathrm{D}_{2} \mathrm{O}, \mathrm{DSS}, 400 \mathrm{MHz}\right): \delta=2.14\left(\mathrm{~m}, \mathrm{~J}=7.2 \mathrm{~Hz}, 2 \mathrm{H}, \mathrm{H}_{\mathrm{a}}\right), \delta=2.55\left(\mathrm{~m}, \mathrm{~J}=8,8 \mathrm{~Hz}, 2 \mathrm{H}, \mathrm{H}_{\mathrm{b}}\right), \delta=$ $3.80\left(\mathrm{t}, \mathrm{J}=6.8 \mathrm{~Hz}, 1 \mathrm{H}, \mathrm{H}_{\mathrm{c}}\right)$ was dissolved in $1 \mathrm{~mL}$ of ultrapure water (Milli-Q water, Merck Millipore); 2) $50 \mathrm{mmol}$ of D-glutamic acid ( $\geq 99 \%$ pure); m.p.: $210-211^{\circ} \mathrm{C} .{ }^{1} \mathrm{H}$ RMN NMR $\left(\mathrm{D}_{2} \mathrm{O}, \mathrm{DSS}, 400 \mathrm{MHz}\right)$ : $\delta=2.14\left(\mathrm{~m}, \mathrm{~J}=7.2 \mathrm{~Hz}, 2 \mathrm{H}, \mathrm{H}_{\mathrm{a}}\right), \delta=2.55\left(\mathrm{~m}, \mathrm{~J}=8 \mathrm{~Hz}, 2 \mathrm{H}, \mathrm{H}_{\mathrm{b}}\right), \delta=3.80\left(\mathrm{t}, \mathrm{J}=6,4 \mathrm{~Hz}, 1 \mathrm{H}, \mathrm{H}_{\mathrm{c}}\right)$ was dissolved in $1 \mathrm{~mL}$ of ultrapure water. SCXRD experiments of L-Glu and D-Glu were collected on a Bruker D8-QUEST diffractometer with a $\mathrm{Cu} \mathrm{K}_{\alpha}$ microfocus source $(\lambda=1.5418 \AA$ ) equipped with a CMOS detector $(300$ (2) K). Optical activity of L-Glu and D-Glu was done on a Jasco 710 spectropolarimetrer (Jasco Inc., Easton MD, USA) on a $0.2 \mathrm{~cm}^{3}$ quartz with $1 \mathrm{~mm}$ path-length containing $20 \mathrm{mM}$ Tris- $\mathrm{HCl} \mathrm{pH}$ 8.0, $20 \mathrm{mM} \mathrm{NaF}$ and $6 \mathrm{mM}$ of each L-Glu/D-Glu. A separate experiment was done with a mixture of $3 \mathrm{mM}$ DL-Glu each. Data was reported as positive or negative ellipticity $v s$. wavelength. Solid-state Raman spectra were taken in a Horiba Jobin-Yvon LabRam HR high-resolution Raman microscope, equipped with a charge-coupled device detector and an excitation laser source with a wavelength of $632.8 \mathrm{~nm}$.

After refinement of the Flack parameter [3], the absolute configuration was determined. L-Glu had an absolute configuration "sinister - $S$ " with a Flack parameter value 0.03 (3), whereas D-Glu had an absolute configuration as "rectum - R" and Flack parameter of 0.09 (4) (Figure 1). The optical activity of each enantiomer was evaluated using circular dichroism. An opposite optical activity was found for the two enantiomers (Figure 2a). As expected, an equimolar mixture of L-Glu and D-Glu gave a near zero ellipticity for the 200-260 nm range. Therefore, L-Glu is classified as levorotatory (-) and D-Glu as dextrorotatory $(+)$. Raman spectra showed the main structural characteristics of the compounds, from 
3021 to $2931 \mathrm{~cm}^{-1}$ the stretching modes of the $-\mathrm{NH}_{3}$ and $-\mathrm{CH}_{\mathrm{n}}$ groups are observed, meanwhile the existence of the zwitterionic form of the glutamic acid is confirmed by the bands at 1658 and $1406 \mathrm{~cm}^{-1}$ of the carboxylate group.

In summary, the absolute configuration and the optical activity of the entitled compounds have been established.

References:

[1] S. S. Tate, A. Meister, The Biological Effects of Glutamic Acid and Its Derivatives, edited by V. A. Najjar, (Dordrecht: Springer, Netherlands) pp. 357-368.

[2] W. Vollmer, D. Blanot, M. A. de Pedro, FEMS Microbiology Reviews 32 (2008) pp. 149-167.

[3] H. D. Flack, G. Bernardinelli, Chirality, 20 (2008) pp. 681-690.

[4] The authors thank CONACYT for scholarships Ph.D. scholarship to L. Fox-Uribe, for a postdoctoral scholarship to Y. Soberanes, grant CB-2014-237963 and equipment grant to INFR-2014-01-225455. We also thank Instituto de Biotecnología-UNAM and CIAD for an academic exchange grant.

(a)
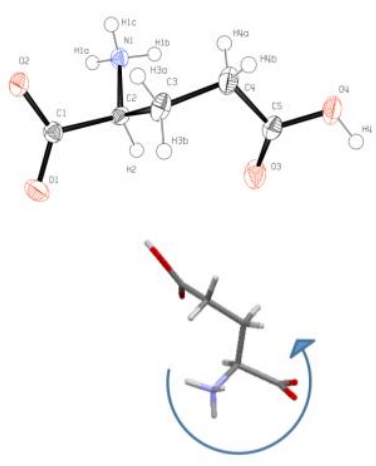

L-Glu (s)

Counterclockwise
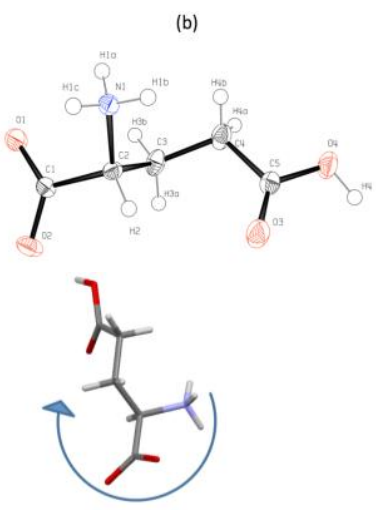

D-Glu (R)

Clockwise

Figure 1. Ortep representation of the asyymetric units of: a) L-Glu and b) D-Glu along with their respective absolute configuration. (atoms are drawn as $50 \%$ probability ellipsoids).

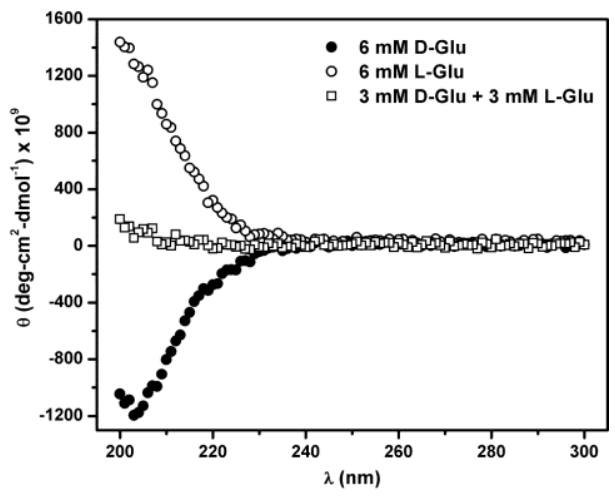

a)

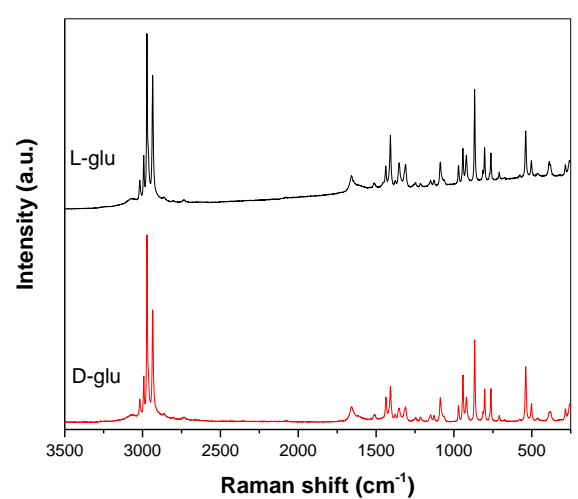

b)

Figure 2. a) Circular Dichroism Spectra of L and D-glutamic acids and the racemic equimolar mixture and b) Raman spectra of L and D-glutamic acids. 